\title{
SSynthesis
}

International Scientific Conference of IT and Business-Related Research

\section{KANALI DISTRIBUCIJE POLJOPRIVREDNIH PROIZVODA SA POSEBNIM OSVRTOM NA PIJACE U SRBIJI}

\author{
DISTRIBUTION CHANNELS FOR AGRICULTURAL PRODUCTS WITH AN EMPHASIS ON THE \\ MARKET PLACE IN SERBIA
}

\author{
Milorad Miljković, Slavko Alčaković \\ Univerzitet Singidunum, Danijelova 32, Beograd, Srbija
}

\begin{abstract}
Apstrakt:
Proizvođači poljoprivrednih proizvoda imaju ograničen izbor prilikom distribucije svojih proizvoda. Najsloženiji problem poljoprivredno prehrambenog proizvoda je pravilan i adekvatan sistem distribucije,a posebno sistem marketing logistike. Zbog specifičnosti poljoprivredne proizvodnje i njenih proizvoda, problemi transporta i skladištenja su veoma kompleksni što zahteva veći broj posrednika u njihovom kretanju od proizvođača do potrošača. Mnoštvo posrednika ima za posledicu visoke troškove prometa poljoprivrednih proizvoda koji se uključuju u cenu a plaćaju ih potrošači. Cene koje proizvođači ostvaruju na pijaci su daleko iznad cena koje važe u otkupu, a nešto su niže od cena u maloprodaji. Autori se pored kanala distribucije bave analizom cena koje se ostvaruju u otkupu i u prometu na pijacama u Srbiji.
\end{abstract}

\section{Ključne reči:}

agrar, kanali distribucije, cene, pijaca.

\section{UVOD}

Kanali distribucije predstavljaju jedan od instrumenata marketing miksa. Njihov zadatak je da omoguće da proizvodi i/ili usluge dođu od proizvođača do potrošača na vreme i u formi pogodnoj za upotrebu, odnosno korišćenje. Posrednici u prometu mogu, ali ne moraju da budu vlasnici proizvoda. Mnogo je važnije i delotvornije poznavati funkcije koje oni obavljaju u savremenoj privredi.

Tokovi povezivanja proizvođača i potrošača su raznovrsni, ali u osnovi se od njih traži da ispune određene ciljeve. Među njima se posebno ističu tri osnovna cilja: sakupljanje, sortiranje i disperziranje. Iz samog naziva datih ciljeva, proističe da je funkcija sakupljanja karakteristična za inicijalnu fazu, a u završnoj fazi su dominantne funkcije disperziranja na veliki broj individualnih potrošača. Unutar sistema distribucije značajne su sve napred navedene funkcije, iako se posebno ističe funkcija sortiranja, posebno u grosističkoj fazi prometa.

Put robe od proizvođača do potrošača, uključujući institucije koje obavljaju te funkcije, kao i veze koje pri tome uspostavljaju, čine ukupan sadržaj kanala marketinga. Dakle, kanali marketinga obuhvataju ukupne tokove robe, novca i informacija koji se odvijaju pri uspostavljanju raznovrsnih veza između pojedinih institucija u sistemu marketinga. Od svih aktivnosti koje obavljaju kanali prometa, posebno se ističu funkcije razmene, fizičkog snabdevanja i usluživanja.

Grupisanje kanala prometa se može izvršiti na više načina, u zavisnosti od specifičnosti proizvoda i veza koje u tom pogledu postoje u odnosu na proizvodnju i potrošnju. Uvažavajući

\section{Abstract:}

Manufacturers of agricultural products have a limited choice of distribution channels for their products. The most complex agricultural food issue is the proper and adequate system of distribution, particularly marketing logistics system. Due to the specificities of agricultural production, transportation and storage issues are very complex, which requires a larger number of intermediaries in their channeling from producers to consumers. A multitude of mediators can lead to high costs of transport of agricultural products included in the price and paid by consumers. Prices that producers achieve at the market place are far above the purchase price, and a bit lower than the retail price. Besides distribution channels, this paper also provides the analysis of prices realized in the market place in Serbia.

\section{Key words:}

agrarian sector, distribution channels, price, market place.

napred date kriterijume, Revzan (1961) je među prvima dao klasifikaciju koja do danas nije izgubila na aktuelnosti i značaju. Sve proizvode je podelio u pet osnovnih kategorija, uvažavajući pri tome zahteve i specifične kanale distribucije između proizvodnje i potrošnje:

1. Kanali distribucije poljoprivrednih proizvoda:

- prerađeni proizvodi (industrijska prerada, finalna potrošnja)

- neprerađeni proizvodi koji se direktno distribuiraju finalnim potrošačima.

2. Kanali distribucije ostalih proizvoda ekstraktivne industrije.

3. Kanali distribucije proizvoda za industrijsku proizvodnu potrošnju:

- proizvodi koji direktno ulaze u proizvodnju novih proizvoda,

- proizvodi koji omogućavaju i olakšavaju dalju proizvodnju,

- proizvodi za neindustrijske tipove potrošnje.

4. Kanali distribucije industrijskih proizvoda za finalnu potrošnju:

- trajni,

- polutrajni,

- netrajni (osim poljoprivrednih).

5. Kanali distribucije usluga:

- poslovne i državne usluge,

- lične usluge. 
Kanali marketinga uobičajeno se posmatraju kroz prizmu prirodnih tokova robe i usluga od proizvođača prema potrošačima. U okviru svakog kanala distribucije, posrednici su povezani raznim vrstama tokova i neodvojivi su od funkcija. Neki od tih tokova su tzv. tokovi unapred (tok prava raspolaganja, promocija), i tokovi unazad (pregovaranje, naručivanje, plaćanje), dok neki idu u oba smera (informacije, preuzimanje rizika) (Revzan, 1961, str. 219-220). Prema tome, treba istaći da kanali marketinga obuhvataju u osnovi tri vrste kanala: kanale prodaje, kanale dostave robe i kanale usluga. Važno je napomenuti da su tokovi robe vidljivi i opipljivi, za razliku od drugih tokova koji su nevidljivi (na primer, tokovi novca, informacija i sl).

Uočljivo je, da proizvođači u većini slučajeva ne vrše direktnu prodaju finalnim potrošačima, već se javljaju brojni posrednici koji obavljaju različite funkcije. Posrednici mogu biti grosisti i detaljisti, ali i brojni agenti i brokeri, kao i ostale uslužne organizacije čiji je osnovni zadatak da pomažu proces kupoprodaje. Posrednici uklanjaju teškoće, olakšavajući na taj način tokove robe i usluga u procesu kupoprodaje. Oni u prometnom lancu uglavnom obavljaju funkcije povezivanja proizvođača i potrošača. Te funkcije su brojne, i uopšte se ne postavlja pitanje da li ih treba obaviti ili ne, nego ko će ih obaviti.

Sve funkcije kanala marketinga imaju tri zajedničke karakteristike:

- za njihovo obavljanje koriste se ograničena sredstva;

- one se često bolje realizuju putem specijalizacije;

- i one mogu biti dodeljenje bilo kom članu kanala (Lovreta, 2007).

\section{KANALI DISTRIBUCIJE POLJOPRIVREDNIH PROIZVODA}

U pokušajima da se koliko-toliko objasne složeni među odnosi na tržištu poljoprivrednih proizvoda, napisane su mnoge knjige i studije. Čitava plejada teoretičara - od engleskog ekonomiste G. Kinga (XVII vek), pa sve do današnjih dana, postavljala je i postavlja hipoteze o zakonitostima koje vladaju na tržištu poljoprivrednih proizvoda. I pored toga, što se došlo do načelnih rešenja, ostaje veliki broj praktičnih i teorijskih problema koje treba rešiti.

Vrlo značajno pitanje koje nije adekvatno rešeno u dosadašnjoj praksi je mesto i uloga kanala distribucije poljoprivrednih proizvoda. Kada govorimo o kanalima distribucije treba naglasiti da proizvođači imaju ograničen izbor mogućih rešenja. Najsloženiji problem u marketingu poljoprivrednih proizvoda je pravilan i adekvatan sistem distribucije, a u okviru nje posebno sistem fizičke distribucije(marketing logistike) (Milisavljević, 1989).

Distributivni kanali kod poljoprivednih proizvoda se u dobroj meri razlikuju od gorenavedenih kanala. Razlike proističu kako zbog poznatih specifičnosti poljoprivredne proizvodnje (uticaj klime i zemljišta, naročito kod biljne proizvodnje), tako i zbog pojave velikog broja proizvođača i potrošača poljoprivrednih proizvoda. Potreba koju poljoprivredni proizvodi zadovoljavaju nije samo biogena, već potreba sa primesama stečene, društveno uslovljene i navikom podržavane psihogene potrebe. Istovremeno, reč je o potrebi koja kao predmet svog zadovoljenja ima na raspolaganju velike količine različitih proizvoda.

Prema tome, masovnost proizvodnje, brojnost proizvođača, što je odlika poljoprivrednih proizvoda, mogućnost upotrebe $\mathrm{u}$ raznim fazama prerade, $s$ jedne strane, i priroda potrebe, njena urgentnost, mnoštvo oblika u kojima se može zadovoljiti, društvena uslovljenost sistema preferencije u potrošnji s druge strane, uslovljava specifičnu karakteristiku kanala distribucije.
Uvid u kanale distribucije pojedinih poljoprivrednih proizvoda, odnosno grupa proizvoda, može se dobiti iz slike 1, kojom su prikazani samo osnovni kanali distribucije poljoprivrednih proizvoda. Napominjemo, da pored napred iznetih, postoji i niz međufaznih kanala distribucije. Međutim, teško je sve to razdvojiti. Koliko navedeni kanali distribucije vrede, zavisi od prirode i tržišne karakteristike svakog proizvoda ponaosob. Neki proizvodi menjaju oblik od proizvođača do potrošača, dok drugi proizvodi ne menjaju oblik. U zavisnosti od karakteristika pojedinih proizvoda, po pravilu, dolazi do većeg ili manjeg odstupanja od prikazanih osnovnih kanala distribucije kod poljoprivrednih proizvoda.

Kanalima distribucije proizvoda iz agrara, u postojećim odnosima, poseban pečat daje prisustvo pijace, koja je objektivna nužnost, čak i onda kada zamenjuje maloprodaju, tako da na tu činjenicu, kao i na posledice koje iz nje proističu moramo još dugo računati.

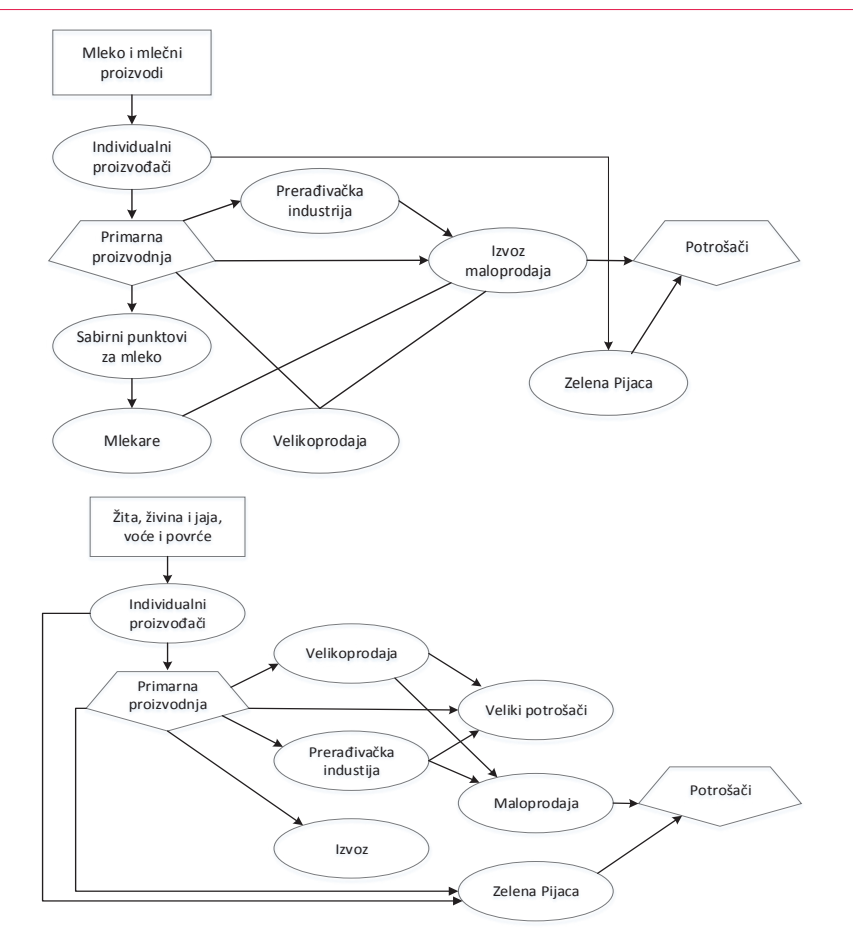

Slika 1. Osnovni tokovi prometa poljoprivrednih proizvoda Izvor: Miljković. M. (1982, str. 104)

Pijaca ili tržnica na malo, kao jedan od kanala distibucije još uvek ima veliki udeo u prometu nekih poljoprivrednih proizvoda. Ona je objektivna nužnost poljoprivrede Srbije, i na njenu egzistenciju treba još dugo računati. Veoma značajno učešće (može se reći dominirajuće) pijaca ima u prometu povrća (prosek za 5 godina - 76,32\%), mlečnih proizvoda (prosek za 5 godina $19,01 \%$ ), i kod voća i grožđa (prosek za 5 godina - 39,01\%), dok je kod drugih grupa proizvoda zanemarujuća (tabela1).

Na visoko učešće pijace u ukupnom prometu povrća utiče veći broj faktora, koji se nalaze na strani proizvodnje (privatni sektor dominira u njegovoj proizvodnji), kao i činjenica da su otkupne cene koje dobijaju proizvođači od otkupnih preduzeća relativno niske u odnosu na nivo cena tih proizvoda u maloprodaji. Prema tome, postojanje relativno visoke razlike između otkupnih i maloprodajnih cena omogućava da se i individualni proizvođači javljaju kao prodavci sopstvenih proizvoda. To znači, ako se poslužimo terminologijom iz političke ekonomije, da metarmofozu R'- N’ obavlja sam proizvođač i da je to njegova nasušna potreba, jer "vreme koje se troši i na kupovinu i na prodaju znači oduzimanje od njegovog radnog vremena” (Marks, 1947). 


\begin{tabular}{|c|c|c|c|c|c|}
\hline $\begin{array}{l}\text { Grupa proiz- } \\
\text { voda/godine }\end{array}$ & 2013 & 2012 & 2011 & 2010 & 2009 \\
\hline \multicolumn{6}{|c|}{ 1. Žito i proizvodi od žita } \\
\hline ukupno & 50.539 & 52.247 & 45.239 & 30.665 & 16.598 \\
\hline pijaca & 627 & 581 & 554 & 434 & 393 \\
\hline $\begin{array}{c}\text { \% učešća pijace } \\
\text { u ukupnom }\end{array}$ & 1,24 & 1,11 & 1,22 & 1,41 & 2,36 \\
\hline \multicolumn{6}{|l|}{ 2. Povrće } \\
\hline ukupno & 13.296 & 10.826 & 10.698 & 9.693 & 8.257 \\
\hline pijaca & 9.995 & 8.374 & 7.786 & 7.642 & 6.399 \\
\hline $\begin{array}{c}\text { \% učešća pijace } \\
\text { u ukupnom }\end{array}$ & 75,17 & 77,35 & 72,78 & 78,84 & 77,5 \\
\hline \multicolumn{6}{|l|}{ 3. Voće i grožđe } \\
\hline ukupno & 17.076 & 14.837 & 13.471 & 12.717 & 11.068 \\
\hline pijaca & 6.059 & 5.696 & 5.406 & 4.752 & 4.876 \\
\hline $\begin{array}{c}\text { \% učešća pijace } \\
\text { u ukupnom }\end{array}$ & 35,48 & 38,39 & 40,13 & 37,36 & 44,05 \\
\hline \multicolumn{6}{|l|}{ 4. Živina i jaja } \\
\hline ukupno & 9.739 & 6.811 & 6.092 & 5.674 & 6.251 \\
\hline pijaca & 4.429 & 4.233 & 3.839 & 3.190 & 3.526 \\
\hline $\begin{array}{c}\text { \% učešća pijace } \\
\text { u ukupnom }\end{array}$ & 45,47 & 62,15 & 55,62 & 56,22 & 56,4 \\
\hline \multicolumn{6}{|c|}{ 5. Mleko i mlečni proizvodi } \\
\hline ukupno & 29.921 & 26.520 & 24.047 & 20.189 & 19.520 \\
\hline pijaca & 5.394 & 4.902 & 4.541 & 4.150 & 3.813 \\
\hline $\begin{array}{c}\text { \% učešća pijace } \\
\text { u ukupnom }\end{array}$ & 18,02 & 18,48 & 18,88 & 20,55 & 19,53 \\
\hline
\end{tabular}

Tabela 1. Učešće pijace u ukupnom prometu poljoprivrednih proizvoda - vrednost u milionima RSD

Izvor: Statistički godišnjak Srbije i obračun autora

Individualni proizvođači u većini slučajeva realizuju svoje proizvode na lokalnim pijacama.

Međutim, razvojem putne infrastrukture i transportnih sredstava, kao i posedovanje transportnih sredstava od strane proizvođača, proizvodi se prodaju i na udaljenijim pijacama, koristeći pri tome razlike u cenama koje se javljaju na pojedinim pijacama, kao i razlike u sezoni pristizanja pojedinih poljoprivrednih proizvoda (posebno povrća i voća). Prodaju na pijaci karakteriše i činjenica da se, uglavnom, nude sveži i relativno kvalitetni proizvodi, a kupci imaju naviku da proizvod biraju, probaju i sl.

Ma koliko troškovi prodaje bili visoki za poljoprivrednika, on će svoje proizvode prodavati neposredno dokle god prisvaja razliku iznad niže otkupne i više maloprodajne cene i naplaćuje svoje prometne usluge (a po njegovoj oceni za utrošeno vreme će dobiti više nego što bi dobio da ostane kod kuće bez posla), troškovi prodaje nemaju za njega značaj koji imaju za trgovinske organizacije.

Cene na pijaci značajno variraju u zavisnosti od intenziteta ponude i tražnje, ali su skoro uvek niže od cena istih proizvoda u maloprodajnim objektima. Na postojanje pijace veliki uticaj ima i razvoj trgovačke mreže, jer trgovina ne obuhvata sve viškove individualnog sektora. Nezahvatanju tržišnih viškova, od strane trgovačke mreže, doprinosi i sama struktura i kvalitet proizvodnje koja se ostvaruje u privatnom sektoru. Vrlo često, a naročito kada se radi o hiperprodukciji, kvalitet proizvoda je na niskom nivou, te trgovina na malo, zbog velikog rizika koji ovi proizvodi nose sa sobom, nije zainteresovana za sve proizvode.

Zbog takve situacije, proizvođač mora da ih proda i da ih iznosi na pijacu, nezavisno od toga šta će dobiti za realizovane

proizvode. Širok asortiman proizvoda u pogledu kvaliteta ima i dobrih strana, jer na taj način mogu da se zadovolje potrebe različitih kategorija potrošača, $s$ obzirom na visinu dohotka. $\mathrm{S}$ druge strane, pod uticajem pijace, individualna gazdinstva se pre ili kasnije specijalizuju za proizvodnju pojedinih grupa poljoprivrednih proizvoda, koje plasiraju na njoj. Ekonomski položaj tih gazdistava je bolji, jer su komparativne prednosti (blizina tržišta odnosno pijace, infrastruktura, prirodni uslovi i sl.) dobro iskorišćene.

\section{RAZLIKE IZMEĐU CENA NA PIJACI, OTKUPNIH I MALOPRODAJNIH CENA}

Ova pitanje je veoma značajno i presudno, jer u krajnjoj liniji utiče na odluku proizvođača da li da svoje proizvode realizuje na pijaci ili da ih plasira preko drugih kanala distribucije, prvenstveno preko trgovinskih preduzeća.

$\mathrm{U}$ tabeli 2 date su cene na pijaci, cene $\mathrm{u}$ otkupu poljoprivrednih proizvoda od individualnog sektora i maloprodajne cene. Cene koje se ostvaruju na pijaci su daleko iznad otkupnih cena, a kod nekih proizvoda se približavaju ceni u maloprodaji. Ostvarene cene koje se postižu na pijaci kod posmatranih proizvoda, nisu bez uticaja na formiranje cena tih proizvoda u trgovačkoj mreži, mada su evidentne razlike u cenama. Najveće razlike u cenama se javljaju kod povrća, što je posledica specifičnosti proizvoda (brza pokvarljivost, osetljivost proizvoda i sl.) a sa druge strane nedovoljne opremljenosti u ovom sektoru trgovine. Napominjemo, da su proizvodi koji se realizuju na pijaci, uglavnom, proizvodi svakodnevne potrošnje.

\begin{tabular}{|c|c|c|c|c|c|}
\hline Proizvod & 2013 & 2012 & 2011 & 2010 & 2009 \\
\hline Krompir \\
\hline Cena na pijaci & 60,67 & 45,51 & 48,29 & 39,21 & 31,5 \\
\hline Otkupna cena & 21,91 & 19,45 & 17,83 & 17,4 & 12,96 \\
\hline Cena u maloprodaji & 59,41 & 44,51 & 47,29 & 38,74 & 31,1 \\
\hline Pasulj \\
\hline Cena na pijaci & 289,68 & 242,27 & 188 & 186,7 & 187,2 \\
\hline Otkupna cena & 250 & 200 & 103,45 & 122,45 & 104,88 \\
\hline Cena u maloprodaji & 298,54 & 250,86 & 193,86 & 197,17 & 101,81 \\
\hline Crni luk & \multicolumn{5}{|l|}{} \\
\hline Cena na pijaci & 60 & 46,3 & 48,67 & 52,62 & 38,97 \\
\hline Otkupna cena & 23,37 & 16,8 & 19,92 & 23,82 & 15,32 \\
\hline Cena u maloprodaji & 55,02 & 37,49 & 43,38 & 53,42 & 38,66 \\
\hline Jabuke za jelo & \multicolumn{5}{|l|}{} \\
\hline Cena na pijaci & 69,16 & 64,33 & 58,66 & 44,83 & 48,04 \\
\hline Otkupna cena & 22,06 & 35,14 & 41,95 & 34,61 & 29,01 \\
\hline Cena u maloprodaji & 69,85 & 76,8 & - & 52,7 & 57,69 \\
\hline Sir & & & \\
\hline Cena na pijaci & 334,86 & 303,53 & 280,94 & 255,97 & 202,52 \\
\hline Otkupna cena & 250 & 185,71 & 194,95 & 206,45 & 199,23 \\
\hline Cena u maloprodaji & 343,63 & 313,34 & 298,23 & 267,16 & 254,24 \\
\hline Sveže mleko & \multicolumn{5}{|l|}{} \\
\hline Cena na pijaci & 65,54 & 58,15 & 55,92 & 50,32 & 44,47 \\
\hline Otkupna cena & 32,84 & 30,33 & 28,56 & 23,33 & 21,65 \\
\hline Cena u maloprodaji & 81,24 & 70,01 & 66,86 & 55,57 & 52,57 \\
\hline
\end{tabular}

Tabela 2. Ostvarene procečne cene po pojedninim proizvodima u din/kg

Izvor: Statistički godišnjak Srbije i obračun autora 
Postojanje velikih razlika između otkupnih cena i cena koje se ostvaruju na pijaci utiče na odluku da se proizvođači opredeljuju za ovaj vid utrživanja svojih proizvoda. Međutim, treba imati u vidu, da celokupna razlika između ostvarenih cena na pijaci i otkupnih cena ne pripada proizvođaču, jer prodaja proizvoda na pijaci iziskuje određene troškove prometa, kao što su takse za zakup prodajnog mesta, pijačarina i neki drugi troškovi za eventualno korišćenje usluga komunalne pijačne uprave.

U prometu preko pijace, značajnu stavku čine transportni troškovi, bilo da se transport obavlja u svojoj režiji ili da se koriste usluge drugih.Učešće korišćenja sopstvenih transportnih sredstava je veoma veliko, što je doprinelo kvalitativnim promenama u prometu poljoprivrednih proizvoda.

\section{REZIME}

Kanali distibucije kod poljoprivrednih proizvoda su specifični i dosta se razlikuju od kanala distribucije industrijskih dobara.Specifičnosti kanala distribucije proističe, pre svega, iz osobenosti same poljoprivrede, kao i postojanje velikog broja subjekata koji su vezani i egzistiraju od nje. Fizički obim proizvodnje ne zavisi samo od primenjene agrotehnike, nego možda u jačoj meri od prirodnih uslova (klimatskih i zemljišnih), dok su potrebe za poljoprivredno-prehrambenim proizvodima vremenski, uglavnom, kontinuirane. Poseban pečat kanalima distribucije poljoprivrednih proizvoda daju pijace, kao objektivna nužnost, posebno kod prodaje proizvoda niske jedinične vrednosti. Uticaj pijace na formiranje cena je značajan, jer se cene formiraju na klasičan način, tj. u zavisnosti od ponude i tražnje. Postojanje evidentne razlike između otkupni cena i cena koje se ostvaruju na pijaci utiče na odluku proizvođača da sami prodaju svoje proizvode. Treba naglasiti da celokupna razlika između ostvarenih i otkupnih cena na pijaci, ne pripada prodavcima, odnosno proizvođačima, jer prodaja na pijaci iziskuje i određene troškove prometa, mada su oni nešto niži za proizvođača nego troškovi prometa koji imaju trgovinske organizacije.

\section{LITERATURA}

Lovreta, S., \& Petković, G. (2007). Trgovinski marketing. Beograd: CID Ekonomskog fakulteta.

Lovreta, S., Radunović, D., Petković,G, \& Končar, J. (2000). Trgovina: teorija i praksa. Beograd: Savremena administracija.

Marks, K. (1947). Kapital : kritika političke ekonomije. Zagreb: Kultura.

Milisavljević,M. (1989) Marketing. Beograd: Savremena administracija.

Miljković, M. (1982). Tržište poljoprivrednih proizvoda u Srbiji: Magistarski rad. Beograd: Ekonomski fakultet.

Revzan, D. A. (1961). Wholesaling in marketing organization. New York: Wiley.

Republički zavod za statistku Srbije. (2010-2014). Statistički godišnjak Srbije. Preuzeto 2. februara 2015. sa

http://webrzs.stat.gov.rs/WebSite/Public/PublicationView. aspx?pKey $=41 \&$ pubType $=1$ 